\title{
Pengaruh Service Quality dan CRM (Customer Relationship Marketing) terhadap Kepuasan Nasabah pada LPD Desa Pakraman Peraupan, Denpasar Utara
}

\author{
Ni Putu Novia Arista Dewi ${ }^{(1)}$ \\ Putu Sri Hartati (2) \\ Gusti Alit Suputra ${ }^{(3)}$ \\ (1)(2)(3) Fakultas Ekonomi Bisnis dan Pariwisata Universitas Hindu Indonesia \\ e-mail: aristanovia22@gmail.com
}

\begin{tabular}{|l|l|l|}
\hline Diterima: 8 Desember 2020 & Direvisi: 22 Desember 2020 & Disetujui: 4 Januari 2021 \\
\hline
\end{tabular}

\begin{abstract}
In the face of intense competition between financial institutions in the Pakraman Peraupan Village LPD, it is demanded to be able to satisfy its customers by providing good service so as to satisfy customers. The purpose of this study was to determine the effect of service quality and customer relationship management (CRM) on customer satisfaction partially and simultaneously. The sample in this study were 96 respondents from Pakraman Peraupan Village LPD customers with multiple linear regression as the analysis technique used. Based on the research results it can be seen that, (1) service quality has a significant positive effect on customer satisfaction, (2) CRM has a significant positive effect on customer satisfaction, and (3) simultaneously service quality and CRM have a significant effect on customer satisfaction. Suggestions that can be given in this research are the LPD Pakraman Peraupan Village, North Denpasar, which is expected to be faster and more responsive in resolving customer complaints, providing training for employees who are still lacking in providing services and providing maximum quality of service and CRM.
\end{abstract}

Keywords: service quality, customer relationship management, customer satisfaction

\begin{abstract}
ABSTRAK
Dalam menghadapi ketatnya persaingan antar lembaga keuangan yang ada LPD Desa Pakraman Peraupan, dituntut dapat memuaskan nasabahnya dengan memberikan pelayanan yang baik sehingga dapat memuaskan pelanggan. Tujuan penelitian ini adalah untuk mengetahui pengaruh service quality dan customer relationship management (CRM) terhadap kepuasan nasabah secara parsial dan simultan. Sampel dalam penelitian ini adalah nasabah LPD Desa Pakraman Peraupan sebanyak 96 orang responden dengan regresi linear berganda sebagai teknik analisis yang digunakan. Berdasarkan hasil penelitian dapat dilihat bahwa, (1) kualitas pelayanan berpengaruh positif signifikan terhadap kepuasan nasabah, (2) CRM berpengaruh positif signifikan terhadap kepuasan nasabah, dan (3) secara simultan kualitas pelayanan dan CRM berpengaruh signifikan terhadap kepuasan nasabah. Saran yang dapat diberikan pada penelitian ini adalah LPD Desa Pakraman Peraupan, Denpasar Utara diharapkan agar lebih cepat dan tanggap dalam menyelesaikan keluhan nasabah, memberikan pelatihan pada karyawan yang masih kurang dalam memberikan pelayanan dan memberikan kualitas pelayaan dan CRM dengan maksimal.
\end{abstract}

Kata kunci: service quality, customer elationship management, kepuasan nasabah 


\section{Pendahuluan}

Lembaga Perkreditan Desa (LPD) merupakan salah satu lembaga keuangan yang terbesar di wilayah Bali merupakan bisnis jasa keuangan yang di kelola oleh desa Pakraman atau Desa Adat. Bukan hanya LPD ada beberapa lembaga keuangan mikro di Bali, yang salah satunya adalah Koperasi. Persaingan antara LPD dan koperasi saat ini bisa di bilang sangat ketat, karena samasama melayani masyarakat Desa Adat di bidang jasa keuangan. Sebagai lembaga keuangan, tentunya LPD juga harus bersaing dengan lembaga keuangan lainnya yang tentu saja lebih prosesional seperti bank umum maupun bank perkreditan rakyat (BPR) sehingga penting bagi LPD untuk memperhatikan kepuasan nasabahnya.

Untuk menciptakan kepuasan nasabah, maka dapat dilakukan dengan memberi pelayanan yang berkualitas sesuai dengan harapan nasabah. Kualitas pelayanan merupakan kemampuan suatu penyedia jasa untuk menyampaikan pelayanan dengan tingkat keunggulan tertentu dan kemampuan penyedia jasa untuk mengendalikan keunggulan tersebut demi memenuhi harapan pelanggan. Ketika pelayanan yang diterima oleh pelanggan sesuai atau bahkan melebihi harapan pelanggan maka akan tercipta kepuasan. Pengaruh kualitas pelayanan terhadap kepuasan telah dibuktikan oleh penelitian yang dilakukan oleh Karwini dan Suryanto (2016) yang membuktikan bahwa kualitas pelayanan berpengaruh positif dan signifikan terhadap kepuasan pelanggan.

Selain kualitas pelayanan, faktor berikutnya yang dapat menciptakan kepuasan pelanggan adalah customer relationship management (CRM) yang bertujuan untuk membangun hubungan baik antara penyedia jasa dengan pelanggan dalam jangka panjang dengan mengkombinasikan kecepatan respon serta membangun interaksi yang tinggi dengan pelanggan (Winter, 2001). Penelitian yang dilakukan oleh Woran, dkk (2016) dan Thirkell (2004) membuktikan bahwa CRM berpengaruh positif dan signifikan terhadap kepuasan nasabah. Penerapan CRM memegang perananan penting bagi keberlangsungan hubungan antara perusahaan dengan pelanggan.

Kotler (dalam Tjiptono, 2014:354) mengungkapkan kepuasan merupakan tingkat perasaan dimana seseorang menyatakan hasil perbandingan atas kinerja produk/jasa yang diterima dan diharapkan. Kepuasan adalah perasaan senang atau kecewa seseorang yang timbul karena membandingkan kinerja yang dipersepsikan (produk atau hasil) terhadap ekspetasi mereka (Kotler dan Keller, 2009:138). Inti dari konsep kepuasan pelanggan adalah menemukan keseimbangan antara harapan pelanggan dan kenyataan atau kinerja yang diterima oleh pelanggan, atau lebih baik jika perusahaan mampu melampaui harapan pelanggan.

LPD Desa Pakraman Peraupan, Denpasar Utara sebagai lembaga intermediasi yaitu lembaga yang menarik dana dari masyarakat dan menyalurkannya ke masyarakat dalam bentuk 
kredit, tabungan, dan deposito, berusaha memberikan pelayanan yang sebaik-baiknya terhadap nasabah, sejak awal berdiri telah melakukan upaya dalam membangun kualitas pelayanan dan menciptakan, mempertahankan dan meningkatkan hubungan-hubungan yang kuat dengan para nasabah dan membangun hubungan jangka panjang dengan nasabah. Adanya penurunan jumlah nasabah pada tahun 2016 sebesar 8,76\% mengindikasikan adanya permasalahan pada kepuasan pelanggan, karena pelanggan yang tidak puas memiliki kecendrungan untuk berpindah ke lembaga keuangan lainnya.

Tujuan penelitian ini adalah (1) untuk mengetahui pengaruh service quality terhadap kepuasan nasabah pada LPD Desa Pakraman Peraupan, Denpasar Utara, (2) untuk mengetahui pengaruh CRM (customer relationship marketing) secara parsial terhadap kepuasan nasabah pada LPD Desa Pakraman Peraupan, Denpasar Utara, dan (3) untuk mengetahui pengaruh service quality dan CRM (customer relationship marketing) secara simultan terhadap kepuasan nasabah pada LPD Desa Pakraman Peraupan, Denpasar Utara.

\section{Telaah Literatur dan Kajian Pustaka}

\section{Kepuasan Nasabah}

Menurut Kotler (2009:177) kepuasan adalah perasaan senang atau kecewa seseorang yang timbul setelah membandingkan kinerja (hasil) produk yang diperkirakan terhadap kinerja (hasil) yang diharapkan. Jika kinerja memenuhi harapan pelanggan puas. Jika kinerja melebihi harapan, nasabaah amat puas atau senang, sedangkan nasabah adalah seseorang yang secara kontinu dan berulang kali datang ke suatu tempat yang sama untuk memuaskan keinginan dengan memiliki suatu produk atau pendapatan suatau jasa dan membayar produk atau jasa tersebut (Lupiyoadi (2013:212).

\section{Service Quality (Kualitas Pelayanan)}

Menurut Kotler (2002:83) kualitas pelayanan suatu perusahaan adalah setiap tindakan atau kegiatan yang dapat ditawarkan oleh suatu pihak kepada pihak yang lain, yang pada dasarnya tidak berwujud atau tidak mengakibatkan kepemilikan apapun. Tjiptono (2007) mendefinisikan kualitas pelayanan dapat diartikan sebagai upaya pemenuhan kebutuhan dan keinginan konsumen serta ketepatan penyampaianya dalam mengimbangi harapan konsumen itu sendiri.

\section{CRM (Customer Relationship Marketing)}

Menurut Lupiyoadi (1009:6) CRM menekankan pada usaha menarik dan mempertahankan pelanggan melalui peningkatan hubungan perusahaan dengan pelanggannya. Menurut Kotler dan Keller (2009:148) CRM (customer relationship management) adalah proses mengelola informasi 
rincian tentang pelanggan perorangan dan semua "titik kontak" pelanggan secara seksama untuk memaksimalkan loyalitas pelanggan.

Hipotesis yang dirumuskan dalam penelitian ini adalah, (H1) diduga servis quality atau kualitas pelayanan berpengaruh positif dan signifikan terhadap kepuasan nasabah LPD Desa Adat Peraupan, Denpasar Utara, (H2) diduga cutomer relationship marketing atau CRM berpengaruh positif dan signifikan terhadap kepuasan nasabah LPD Desa Adat Peraupan, Denpasar Utara, (H3) diduga servis quality dan CRM berpengaruh positif dan signifikan terhadap kepuasan nasabah LPD Desa Adat Peraupan, Denpasar Utara.

\section{Metode Penelitian}

Penelitian ini merupakan penelitian deskriptif, metode yang digunakan dalam penelitian ini adalah metode survei, pengumpulan data diperoleh dengan menggunakan angket berupa pernyataan tertulis yang diberikan responden untuk diisi dengan keadaan sebenarnya untuk dapat mengetahui seberapa besar pengaruh variabel bebas service quality atau kualitas pelayanan (X1) dan customer relationship marketing (CRM/X2) terhadap kepuasan nasabah (Y) LPD Desa Pakraman Peraupan, Denpasar Utara. Populasi dalam penelitian ini adalah nasabah LPD Desa Pakraman Peraupan periode tahun 2014-2018 yang berjumlah 10.110 orang. Penentuan jumlah sampel dilakukan dengan menggunakan rumus Slovin sehingga ditetapkan sampel sebanyak 96 orang nasabah dengan menggunakan teknik accidental sampling. Pengumpulan data dilakukan dengan menggunakan kuisioner untuk megnukur persepsi responden terhadap service quality, CRM, dan kepuasan nasabah dengan menggunakan skala Likert lima pilihan jawaban yaitu sangat setuju (SS) diberi nilai 5, setuju (S) diberi nilai 4, kurang setuju (KS) diberi nilai 3, tidak setuju (TS) diberi nilai 2, dan sangat tidak setuju (STS) diberi nilai 1. Untuk menjawab hipotesis yang diajukan, maka penelitian ini menggunakan teknik analisis regresi linear berganda.

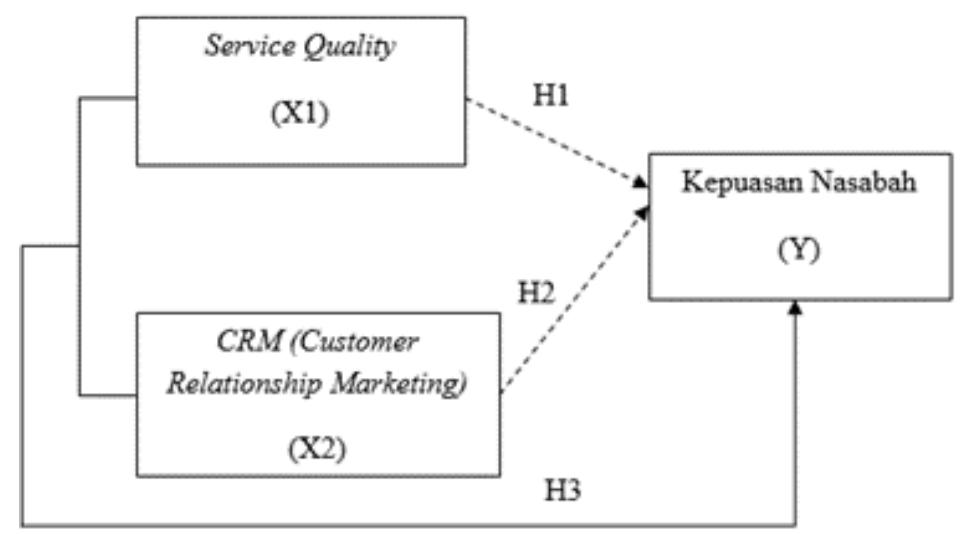

Gambar 1. Kerangka Pemikiran 


\section{Hasil Penelitian dan Pembahasan}

Pada Tabel 1 dapat dilihat bahwa seluruh indikator variabel pada penelitian ini yaitu service quality (kualitas pelayanan), CRM dan kepuasan nasabah valid karena memiliki nilai koefisien korelasi lebih besar dari 0,30 dan reliabel dengan cronbach's alpha lebih dari 0,60.

\section{Tabel 1. Hasil Uji Validitas dan Reliabilitas}

\begin{tabular}{|c|c|c|c|c|c|}
\hline \multirow{2}{*}{ Variabel } & \multirow{2}{*}{ Item Pertanyaan } & \multicolumn{2}{|c|}{ Validitas } & \multicolumn{2}{|c|}{ Reliabilitas } \\
\hline & & Koefisien Korelasi & Ket. & Cronbach's Alpha & Ket. \\
\hline \multirow{10}{*}{ Kualitas Pelayanan (X1) } & $\mathrm{X} 1.1$ & 0,887 & Valid & \multirow{10}{*}{0,97} & \multirow{10}{*}{ Reliabel } \\
\hline & $\mathrm{X} 1.2$ & 0,845 & Valid & & \\
\hline & $\mathrm{X} 1.3$ & 0,915 & Valid & & \\
\hline & $\mathrm{X} 1.4$ & 0,883 & Valid & & \\
\hline & $\mathrm{X} 1.5$ & 0,848 & Valid & & \\
\hline & X1.6 & 0,897 & Valid & & \\
\hline & $\mathrm{X} 1.7$ & 0,919 & Valid & & \\
\hline & $\mathrm{X} 1.8$ & 0,883 & Valid & & \\
\hline & X1.9 & 0,913 & Valid & & \\
\hline & $\mathrm{X} 1.10$ & 0,9 & Valid & & \\
\hline \multirow{6}{*}{ CRM (X2) } & $\mathrm{X} 2.1$ & 0,907 & Valid & \multirow{6}{*}{0,936} & \multirow{6}{*}{ Reliabel } \\
\hline & $\mathrm{X} 2.2$ & 0,911 & Valid & & \\
\hline & $\mathrm{X} 2.3$ & 0,865 & Valid & & \\
\hline & $\mathrm{X} 2.4$ & 0,869 & Valid & & \\
\hline & $\mathrm{X} 2.5$ & 0,848 & Valid & & \\
\hline & $\mathrm{X} 2.6$ & 0,826 & Valid & & \\
\hline \multirow{6}{*}{ Kepuasan Nasbaah (Y) } & Y.1 & 0,843 & Valid & \multirow{6}{*}{0,924} & \multirow{6}{*}{ Reliabel } \\
\hline & Y.2 & 0,858 & Valid & & \\
\hline & Y.3 & 0,842 & Valid & & \\
\hline & Y.4 & 0,815 & Valid & & \\
\hline & Y.5 & 0,881 & Valid & & \\
\hline & Y.6 & 0,871 & Valid & & \\
\hline
\end{tabular}

Sumber: data diolah, 2020

Tabel 2. Karakteristik Responden

\begin{tabular}{|c|c|c|c|}
\hline Kriteria & Pilihan & Jumlah (orang) & Persentase $(\%)$ \\
\hline \multirow{2}{*}{ Jenis Kelamin } & Laki-laki & 46 & 47,9 \\
\hline & Perempuan & 50 & 52,1 \\
\hline \multirow{4}{*}{ Umur } & $17-22$ tahun & 9 & 9,4 \\
\hline & $23-38$ tahun & 13 & 13,5 \\
\hline & $29-34$ tahun & 30 & 31,3 \\
\hline & $>34$ tahun & 44 & 45,8 \\
\hline \multirow{4}{*}{ Tingkat Pendidikan } & SMP/SLTP & 11 & 11,5 \\
\hline & SMA/SMK/SLTA & 36 & 36,4 \\
\hline & Diploma & 25 & 25 \\
\hline & $\mathrm{S} 1$ & 27 & 27,1 \\
\hline \multirow{5}{*}{ Pekerjaan } & Pelajar / Mahasiswa & 12 & 12,5 \\
\hline & Pegawai Swasta & 44 & 45,8 \\
\hline & PNS & 10 & 10,4 \\
\hline & Wirausaha & 22 & 22,9 \\
\hline & Ibu Rumah Tangga & 8 & 8,3 \\
\hline \multirow{4}{*}{ Penghasilan } & $<$ Rp. 2.000 .000 & 28 & 29,2 \\
\hline & Rp. 2.00.000-Rp. 3.000 .000 & 33 & 34,3 \\
\hline & Rp. 3.000 .000 s/d Rp. 4.000 .000 & 25 & 26 \\
\hline & $>$ Rp.4.000.000 & 10 & 10,4 \\
\hline
\end{tabular}

Sumber : data diolah, 2020 
Karakteristik 96 responden dijelaskan ke dalam lima kategori yang dapat dilihat pada Tabel 2. Berdasarkan jenis kelamin responden laki-laki lebih banyak daripada responden perempuan yaitu sebanyak 50 orang $(52,1 \%)$, sedangkan responden laki-laki hanya 46 orang $(47,9 \%)$. Berdasarkan usia, responden yang terbanyak adalah berusia >34 tahun sebanyak 44 orang $(45,8 \%)$ dan terendah usia 17-29 tahun sebanyak 9 orang $(9,4 \%)$. Berdasarkan tingkat pendidikan responden yang terbanyak adalah berpendidikan SMA/SMK/SLTA sebanyak 36 orang $(36,4 \%)$ dan terendah berpendidikan SMP/SLTP sebanyak 11 orang (11,5\%). Menurut pekerjaan, responden yang terbanyak adalah berprofesi sebagai pegawai swasta sebanyak 44 orang $(45,8 \%)$ dan terendah ibu rumah tangga sebanyak 8 orang $(8,3 \%)$. Berdasarkan penghasilan, responden yang terbanyak adalah berpenghasilan Rp. 2.00.000-Rp. 3.000.000 sebanyak 33 orang (34,3\%) dan terendah diatas > Rp.4.000.000 sebanyak 10 orang $(10,4 \%)$.

Pengujian asumsi klasik dengan nilai Asymp. Sig. (2-tailed) pada Tabel 3 adalah sebesar 0,586 yaitu lebih besar dari 0,05 yang menunjukan bahwa data terdistribusi secara normal, sehingga dapat disimpulkan bahwa model memenuhi asumsi normalitas. Tabel 4 menunjukkan seluruh variabel bebas memiliki nilai tolerance $>0,10$, begitu juga dengan hasil perhitungan nilai VIF, seluruh variabel memiliki nilai VIF $<10$. Hal ini berarti bahwa pada model regresi yang dibuat tidak terdapat gejala multikolinearitas. Tabel 5 menunjukkan masing-masing model memiliki nilai signifikansi lebih besar dari 0,05. Berarti didalam model regresi ini tidak terjadi kesamaan varian dari residual satu pengamatan ke pengamatan lainnya atau tidak terjadi heteroskedastisitas.

\section{Tabel 3. Hasil Uji Normalitas}

\begin{tabular}{llr}
\multicolumn{2}{c}{ One-Sample Kolmogorov-Smirnov Test } \\
\hline $\mathrm{N}$ & & Unstandardized Residual \\
Normal Parameters ${ }^{\mathrm{a}, \mathrm{b}}$ & Mean & 96 \\
& Std. Deviation & $0,00 \mathrm{E}+00$ \\
& Absolute & 273.842 .994 \\
Most Extreme Differences & Positive & .079 \\
& Negative & .058 \\
Kolmogorov-Smirnov Z & & -.079 \\
Asymp. Sig. (2-tailed) & & .774 \\
\hline
\end{tabular}

Sumber: data diolah, 2020

\section{Tabel 4. Hasil Uji Multikolinearitas}

\begin{tabular}{|c|c|c|c|c|c|c|c|c|}
\hline \multicolumn{9}{|c|}{ Coefficients $^{\mathrm{a}}$} \\
\hline \multirow{2}{*}{\multicolumn{2}{|c|}{ Model }} & \multicolumn{2}{|c|}{ Unstandardized Coefficients } & \multirow{2}{*}{$\begin{array}{r}\begin{array}{l}\text { Standardized } \\
\text { Coefficients }\end{array} \\
\text { Beta }\end{array}$} & \multirow[t]{2}{*}{$\mathrm{T}$} & \multirow[t]{2}{*}{ Sig. } & \multicolumn{2}{|c|}{$\begin{array}{c}\text { Collinearity } \\
\text { Statistics }\end{array}$} \\
\hline & & $\mathrm{B}$ & Std. Error & & & & Tolerance & VIF \\
\hline \multirow{3}{*}{1} & (Constant) & 3.810 & 1.570 & & 2.428 & .017 & & \\
\hline & Service Quality & .259 & .045 & .470 & 5.802 & .000 & 670 & 1.494 \\
\hline & CRM & .386 & .079 & .396 & 4.888 & .000 & .670 & 1.494 \\
\hline
\end{tabular}

Sumber: data diolah, 2020 
Tabel 5. Hasil Uji Heteroskedastisitas

\begin{tabular}{|c|c|c|c|c|c|c|}
\hline \multicolumn{7}{|c|}{ Coefficients ${ }^{\mathrm{a}}$} \\
\hline & \multirow[b]{2}{*}{ Model } & \multicolumn{2}{|c|}{ Unstandardized Coefficients } & \multirow{2}{*}{$\frac{\text { Standardized Coefficients }}{\text { Beta }}$} & \multirow[t]{2}{*}{$\mathrm{T}$} & \multirow[t]{2}{*}{ Sig. } \\
\hline & & $\mathrm{B}$ & Std. Error & & & \\
\hline \multirow{3}{*}{1} & (Constant) & 2.810 & .987 & & 2.847 & .005 \\
\hline & Service Quality & -.047 & .028 & -.209 & -1.676 & .097 \\
\hline & CRM & .046 & .050 & .116 & .930 & .355 \\
\hline
\end{tabular}

Sumber: data diolah, 2020

Analisis regresi linier berganda dilakukan untuk mengetahui hubungan dan pengaruh antar variabel bebas terhadap variabel terikat. Berdasarkan Tabel 6 dapat diketahui persamaan regresinya ini adalah : $\mathrm{Y}=3,810+0,259 \mathrm{X} 1+0,386 \mathrm{X} 2$.

Tabel 6. Hasil Analisis regresi Linear Berganda

\begin{tabular}{llccccc}
\hline \multirow{2}{*}{ Model } & \multicolumn{2}{c}{ Unstandardized Coefficients } & Standardized Coefficients & \multirow{2}{*}{ T } & \multirow{2}{*}{ Sig. } \\
\cline { 2 - 4 } & B & Std. Error & Beta & & \\
\hline \multirow{2}{*}{ (Constant) } & 3.810 & 1.570 & & 2.428 & .017 \\
Service Quality & .259 & .045 & .470 & 5.802 & .000 \\
& CRM & .386 & .079 & .396 & 4.888 & .000 \\
\hline
\end{tabular}

Sumber: data diolah, 2020

Untuk menjawab hipotesis $1(\mathrm{H} 1)$ dan hipotesis 2 (H2) maka digunakan uji signifkansi parsial (uji-t) dengan berdasarkan pada hasil analisis regresi linear berganda pada Tabel 6 yang dapat dikemukakan sebagai berikut.

1. Pengaruh service quality (kualitas pelayanan) terhadap kepuasan nasabah pada LPD Desa Pakraman Peraupan, Denpasar Utara

Dari hasil penelitian diketahui adanya pengaruh positif service quality (kualitas pelayanan) terhadap kepuasan nasabah. Hal ini dibuktikan dengan koefisien regresi sebesar 0,259 (positif) dengan nilai t-hitung $(5,802)>$ t-tabel $(1,985)$ dan nilai sig. $0,000<0,005$ maka H1 diterima. Dengan demikian hipotesis yang menyatakan bahwa service quality (kualitas pelayanan) (X1) berpengaruh positif dan signifikan secara parsial terhadap kepuasan nasabah (Y) diterima. Hal ini berarti semakin baik kualitas pelayanan yang diberikan maka akan meningkatkan kepuasan nasabah LPD Desa Pakraman Peraupan, Denpasar Utara. Hasil penelitian ini juga mendukung penelitian sebelumnya yang dilakukan oleh Karwini dan Suryanto (2016) yang menyatakan bahwa service quality (kualitas pelayanan) berpengaruh positif terhadap kepuasan nasabah.

2. Pengaruh CRM terhadap kepuasan nasabah pada LPD Desa Pakraman Peraupan, Denpasar Utara

Dari hasil penelitian diketahui adanya pengaruh positif CRM terhadap kepuasan nasabah. Hal ini dibuktikan dengan koefisien regresi bernilai 0,386 (positif) dengan nilai t-hitung $(4,888)>$ t-tabel $(1,985)$ dan nilai sig. 0,000 < 0,05 maka H1 diterima. Dengan demikian hipotesis yang menyatakan bahwa CRM (X2) berpengaruh positif dan signifikan secara parsial terhadap kepuasan $\frac{\text { nasabah (Y) diterima. Hal ini berarti semakin baik customer relationship marketing yang }}{\text { Ni Putu Novia Arista Dewi, dkk } \mid 83}$ 
diterapkan maka akan meningkatkan kepuasan nasabah LPD Desa Adat Peraupan, Denpasar Utara. Hasil penelitian ini juga mendukung penelitian sebelumnya yang dilakukan oleh Woran, et. al (2016) yang menyatakan bahwa CRM berpengaruh positif terhadap kepuasan nasabah.

Pengaruh secara simultan variabel service quality (kualitas pelayanan) dan CRM terhadap keputusan pembelian dapat dilihat pada Tabel 7. Nilai F-hitung $(67,331)>$ F-tabel $(3,09)$ dan nilai sig 0,000 maka H3 diterima. Ini berarti bahwa secara statistik untuk uji satu sisi pada taraf kepercayaan $(\alpha)=5 \%$, secara simultan service quality (kualitas pelayanan) (X1) dan CRM (X2) berpengaruh positif dan signifikan terhadap kepuasan nasabah (Y). Dengan demikian hipotesis yang menyatakan bahwa service quality (kualitas pelayanan) (X1) dan CRM (X2) berpengaruh positif dan signifikan secara simultan terhadap kepuasan nasabah (Y) teruji kebenarannya. Hal ini berarti semakin baik service quality (kualitas pelayanan) dan customer relationship marketing maka akan meningkatkan kepuasan nasabah LPD Desa Pakraman Peraupan, Denpasar Utara.

\section{Tabel 7. Hasil Uji F}

\begin{tabular}{llccccc}
\multicolumn{7}{c}{ ANOVA $^{\mathrm{a}}$} \\
\hline & Model & Sum of Squares & Df & Mean Square & F & Sig. \\
\hline \multirow{3}{*}{1} & Regression & 1.031 .553 & 2 & 515.777 & 67.331 & $.000^{\mathrm{b}}$ \\
& Residual & 712.405 & 93 & 7.660 & & \\
& Total & 1.743 .958 & 95 & & & \\
\hline
\end{tabular}

Sumber: data diolah, 2020

\section{Simpulan}

Berdasarkan data yang diperoleh dari hasil analisis dapat ditarik kesimpulan, service quality (kualitas pelayanan) berpengaruh positif dan signifikan secara parsial terhadap kepuasan nasabah pada LPD Desa Pakraman Peraupan, Denpasar Utara. CRM berpengaruh positif dan signifikan secara parsial terhadap kepuasan nasabah pada LPD Desa Pakraman Peraupan, Denpasar Utara. Service quality (kualitas pelayanan) dan CRM berpengaruh secara simultan terhadap kepuasan nasabah pada LPD Desa Pakraman Peraupan, Denpasar Utara.

Rekomendasi penelitian yaitu LPD Desa Pakraman Peraupan, Denpasar Utara diharapkan agar lebih cepat dan tanggap dalam menyelesaikan keluhan nasabah, memberikan pelatihan pada karyawan yang masih kurang dalam memberikan pelayanan, selalu memberikan service quality (kualitas pelayanan) dan CRM dengan maksimal. Untuk penelitian selanjutnya, agar dapat dilakukan penelitian dan pengkajian lebih dalam terhadap faktor-faktor lain yang tidak diteliti dalam penelitian ini yang dapat mempengaruhi kepuasan selain service quality (kualitas pelayanan) dan CRM. Agar nantinya dapat mengetahui tindakan apa yang harus dilakukan LPD Desa Pakraman Peraupan, Denpasar Utara untuk meningkatkan kepuasan nasabah. 


\section{Daftar Pustaka}

Anggita Putri Iriandini, Edy Yulianto, M. Kholid Mawardi. 2015. Pengaruh Customer Relationship Management (CRM) Terhadap Kepuasan Pelanggan Dan Loyalitas Pelangga. Universitas Brawijaya

Andriyan Dwi Putra.2018. Analisa Kepuasan Pelanggan Event Organizer XYZ menggunakan Metode Service Quality. Universitas Amikom Yogyakarta

Conny Sondakh. 2014. Kualitas Layanan, Citra Merek Dan Pengaruhnya Terhadap Kepuasan Nasabah Dan Loyalitas Nasabah Tabungan (Studi Pada Nasabah Taplus BNI Cabang Manado). Universitas Sam Ratulangi

Dita Septi Setiarini, Sendhang Nurseto. 2017. The Effect of Service Quality and Customer Value To Customer Satisfaction. Universitas Diponegoro

Gusti Ayu Putu Suarni, Lulup Endah Trupalupi1, Iyus Akhmad Haris. 2014. Analisis Faktor Yang Mempengaruhi Keputusan Nasabah Dalam Pengambilan Kredit Pada Lpd (Lembaga Perkreditan Desa) Desa Pakraman Manggissari. Universitas Pendidikan Ganesha Singaraja, Indonesia

Hari Mulyadi, Febsri Susanti. 2011. Pengaruh Penerapan Strategi Customer Relationshi Marketing Terhadap Kepuasan Nasabah Pada PT. Pro Car International Finance Cabang Padang. Sekolah Tinggi Ilmu Ekonomi KBP

Ida Ayu Komang Firna Erawati, I Dewa Nyoman Badera. Issn: 2302 - 8556 .2015. Pengaruh Jumlah Kredit, Tabungan, Deposito Dan Pengalaman Badan Pengawas Pada Profitabilitas. Fakultas Ekonomi Dan Bisnis Universitas Udayana, Bali, Indonesia

Imroatul Khasanah, Octarina Dina Pertiwi. 2010. Analisis Pengaruh Kualitas Pelayanan terhadap Kepuasan Konsumen RS St. Elisabeth Semarang. Universitas Diponegoro

I Made Aditya Jaya Permana, I Ketut Nurcahya. 2012. Pengaruh Kualitas Pelayanan Terhadap Kepuasan Dan Loyalitas Nasabah Pada LPD Desa Adat Kedonganan. Fakultas Ekonomi dan Bisnis Universitas Udayana (UNUD) Bali, Indonesia

Indah Umar, Silcyljeova Moniharapon, Jane Grace Poluan. 2016. Analisis Pengaruh Costumer Relationship Marketing, Nilai Nasabah Dan Keunggulan Produk Terhadap Loyalitas Nasabah Pada Pt. Pegadaian (Persero) Kanwil V Manado. Universitas Sam Ratulangi

Natalia Ribka Lumempow, Silvya Mandey, Jopie Jorie Rotinsulu. 2015. Analisis Faktor-Faktor Kualitas Pelayanan Terhadap Kepuasan Nasabah Pada PT. Bank Mandiri Tbk Cabang Bahu Mall Manado. Universitas Sam Ratulangi Manado

Nita Woran, Altje Tumbel, Paulina Van Rate. 2016. Pengaruh Costumer Relationship Marketing, Nilai, Keunggulan Produk Dan Kepuasan Terhadap Loyalitas Nasabah (Studi Pada Bank Mega J1. Piere Tendean Mega Mall Manado). Universitas Sam Ratulangi

Ni Putu Dharma Diyanthini, Ni Ketut Seminari. 2013. Pengaruh Citra Perusahaan, Promosi Penjualan Dan Kualitas Pelayanan Terhadap Kepuasan Nasabah Pada Lpd Desa Pakraman Panjer. Universitas Udayana

Ni Ketut Karwini, I Wayan Dodi Suryanto. 2016. Analisis Kualitas Pelayanan Dan Dampaknya Terhadap Kepuasan Nasabah Pada Lembaga Perkreditan Desa (LPD) Desa Adat Tibubiu Kerambitan Tabanan. Stimi Handayani Denpasar

Ni Made Sugiarthi, I Made Nuridja, Luh Indrayani. 2014. Pengaruh Kualitas Pelayanan Terhadap Kepuasan Nasabah Pada PT BPR Ulatidana Rahayu Di Kecamatan Sukawati Tahun 2012. Universitas Pendidikan Ganesha

Sri Utami, M. Hufron, Afi Rachmat. 2007. Pengaruh Customer Relationship Management (Crm) Terhadap Kepuasan Konsumen Studi Kasus Pada Konsumen Rumah Makan Ayam Nelongso Malang. Universitas Islam Malang

Ustantia Pratiwi Putri, Suharyono, Yusri Abdillah. 2014. Pengaruh Relationship Marketing Terhadap Kepuasan Dan Loyalitas Nasabah. Universitas Brawijaya Malang 